\title{
Analisis Tingkat Kepuasan Konsumen Terhadap Kualitas Layanan pada Minimarket SK
}

\author{
Tri Joko Wibowo ${ }^{1}$, Muhammad Nurul Ardhi ${ }^{2}$ \\ Jurusan Teknik Industri, Fakultas Teknik, Universitas Serang Raya \\ Jl. Raya Cilegon No.KM.5, Drangong, Kec. Taktakan, Kota Serang, Banten 42116 \\ Email : ${ }^{1)}$ rb.bowo@gmail.com, ${ }^{2)}$ m.nurul.ardhi@gmail.com
}

\begin{abstract}
Abstrak
Minimarket SK merupakan minimarket yang tergolong Usaha Kecil dan Menengah (UKM). Sebagaimana karakteristik umum UKM yaitu lemah dalam hal pengelolaan pelanggan. Minimarket SK belum melakukan evaluasi terhadap layanannya sehingga belum diketahui apakah pelanggan telah merasa puas atau belum atas pelayanan yang telah diberikan oleh Minimarket SK. Tujuan penelitian ini adalah untuk mengetahui tingkat kepuasan pelanggan yang menggunakan jasa pelayanan Minimarket SK. Pengukuran kualitas pelayanan dilakukan dengan menggunakan metode Servqual dan CSI (Customer Satisfaction Index). Untuk menindaklanjuti hasil pengolahan kuesioner Servqual maka dipergunakan metode IPA (Importance Performance Analysis) untuk mengetahui area prioritas perbaikan agar tingkat kepuasan pelanggan mengalamai perbaikan. Hasil penelitian menunjukkan bahwa tingkat kepuasan konsumen secara menyeluruh berdasarkan nilai CSI sebesar $62,86 \%$ dan terletak direntang nilai $61 \%$ - $80 \%$ yang menunjukkan bahwa indeks kepuasan pengunjung secara umum masuk dalam kriteria "Puas", namun beberapa atribut yang ada dalam dimensi servqual memiliki nilai gap yang negatif. Berdasarkan hasil plotting data kuesioner Servqual ke kuadran IPA maka bisa diketahui kinerja pelayanan pelanggan Minimarket SK yang perlu dilakukan perbaikan. Manajemen Minimarket SK perlu melakukan perbaikan pada beberapa hal sebagai berikut : pembayaran bisa menggunakan kartu debit, fasilitas duduk di depan minimarket, ketersediaan barang selalu terjaga, dapat melakukan pembayaran transaksi belanja online dan jaminan komunikasi yang baik antara karyawan dengan konsumen.
\end{abstract}

Kata kunci: customer satisfaction index (CSI), importance performance analysis (IPA), plotting, servqual, UKM

\begin{abstract}
SK Minimarket is a minimarket classified as Small and Medium Enterprises (UKM). As a general characteristic of SMEs, namely weak in terms of customer management. SK Minimarket has not evaluated its services so it is not yet known whether the customer has felt satisfied or not on the services provided by SK Minimarket. The purpose of this study was to determine the level of customer satisfaction using Minimarket SK services. Measurement of service quality is done using the Servqual and CSI (Customer Satisfaction Index) methods. To follow up on the results of the Servqual questionnaire processing, the IPA (Importance Performance Analysis) method is used to determine the priority areas of improvement so that the level of customer satisfaction experiences improvement. The results showed that the level of overall customer satisfaction based on CSI value of $62.86 \%$ and located in the range of $61 \%-80 \%$ which indicates that the index of visitor satisfaction is generally included in the "Satisfied" criteria, but some attributes that exist in the servqual dimension have negative gap value. Based on the results of Servqual questionnaire data plotting into the IPA quadrant, it can be seen the performance of the SK Minimarket customer service that needs to be improved. SK Minimarket Management needs to make improvements in the following matters: payment can use a debit card, sitting facilities in
\end{abstract}


front of a minimarket, availability of goods is always maintained, can make payments for online shopping transactions and guarantees good communication between employees and consumers

Keywords: customer satisfaction index (CSI), importance performance analysis (IPA), plotting, servqual, SME

\section{PENDAHULUAN}

Seperti yang kita ketahui persaingan bisnis retail di Indonesia menunjukan pertumbuhan yang cukup signifikan. Dikarenakan potensi pasar di Indonesia masih cukup besar dan menguatnya usaha kelas menengah dan kecil, telah menambah banyaknya kelompok masyarakat berpenghasilan menengah atas yang memiliki gaya hidup belanja di ritel modern, salah satunya adalah minimarket.

Berdasarkan kuesioner pendahuluan yang disebarkan kepada beberapa responden dan wawancara kepada salah satu karyawan Minimarket SK, terdapat beberapa pelayanan yang telah diberikan dengan baik, namun belum sepenuhnya layanan yang ada di Minimarket SK ditanggapi dengan baik oleh konsumen. Dari pelayanan yang ada di Minimarket SK terdapat beberapa keluhan dari beberapa konsumen yang kurang puas antara lain seperti, kemudahan dalam pembayaran, jaminan komunikasi yang baik antara karyawan dengan konsumen, dan berbagai fasilitas yang lengkap yang diberikan dari pihak manajemen. Dengan adanya keluhan tersebut, maka akan mengakibatkan ketidaknyamanan konsumen dalam berbelanja yang akan membuat kualitas pelayanan yang ada menjadi kurang baik dimata konsumen. Keluhan konsumen merupakan ungkapan ketidakpuasan dari konsumen karna adanya sesuatu yang tidak dapat diterima, baik dengan produk yang ditawarkan maupun dengan pelayanan (Sangadji, Etta dan Sopiah 2013)

Berdasarkan latar belakang dan keluhan yang diketahui dari kuesioner pendahuluan dan wawancara maka penelitian bertujuan untuk mengetahui : 1 . tingkat kepuasan konsumen terhadap kualitas pelayanan yang diberikan oleh Minimarket SK secara menyeluruh, 2. atribut apa saja yang menjadi faktor penentu dalam perbaikan dan 3. area perbaikan yang harus diprioritaskan untuk meningkatkan kualitas pelayanan pada Minimarket SK. Penelitian ini menggunakan metode survey kepuasan pelanggan walaupun sebenarnya pengukuran kepuasan pelanggan tidak hanya dilakukan dengan survey melainkan bisa dengan system keluhan dan saran, ghost shopping dan lost customer analysis (Tjiptono, 2005 di dalam Syukri, 2014)

Sebagai pembanding terdapat penelitian tentang kepuasan pelanggan yang menggabungkan metode IPA (Importance Performance Analysis) dan CSI (Customer Satisfaction Index) seperti penelitian Anggraini, Deoranto \& Ikasari, (2015), Tupamahu \& Hamka (2017), Syukri (2014), Dewi, Restuputri \& Sulaksmi (2015), Rahmasari, Nurmalina \& Priatna (2017), Sumaga (2013) dan Astuty (2014).

\section{METODE PENELITIAN}

\subsection{Langkah Utama Penelitian}

Penelitian ini berlokasi di Minimarket SK, Serang, Banten. Data penelitian diambil pada bulan Juli 2019. Metode dalam penelitian ini adalah 1) metode 
Servqual untuk mengukur kepuasan pelangga dalam lima dimensi yaitu tangibles (bukti fisik), reliability (keandalan), responsiveness (daya tanggap), assurance (jaminan), emphaty (empati), 2). metode Customer Satisfaction Index (CSI) untuk mengetahui tingkat kepuasan pelanggan. Data untuk mengetahui tingkat kepuasan pelanggan diperoleh dari hasil pengisian kuesioner Servqual dan 3) metode Importance Performance Analysis (IPA) untuk mengetahui faktor apa saja yang menjadi penentu dalam perbaikan kepuasan pelanggan.

Penelitian ini diawali dengan melakukan identifikasi masalah melalui proses observasi dan wawancara. Proses identifikasi masalah menghasilkan keputusan yaitu perlunya pengukuran kepuasan pelanggan Minimarket SK. Sebagai minimarket yang masih dalam proses berkembang diperlukan upaya untuk selalu meningkatkan layanan berdasarkan masukan dari pelanggan. Suara pelanggan diambil melalui metode survey kepuasan pelanggan menggunakan metode Servqual. Survey yang dilakukan berjenis pick up survey. Metode pengambilan sampelnya adalah purposive sampling dengan judgment sampling (Jogiyanto, 2016). Metode ini dipilih karena responden dari kuesioner ini adalah hanya para pelanggan dan konsumen Minimarket SK. Hasil dari survey kepuasan pelanggan selanjutnya dianalisa dengan menggunakan metode IPA dan CSI. Hasil analisa metode IPA ditindaklanjuti dengan pemberian saran perbaikan.

Popularitas metode survei Servqual dikarenakan sejumlah keunggulan : Pertama, metode Servqual telah berkembang menjadi standar atau acuan suatu penilaian dalam berbagai dimensi kualitas pelayanan. Kedua, berbagai riset telah menunjukkan bahwa metode Servqual valid untuk berbagai konteks layanan. Ketiga, Pertanyaan Quisioner di interpretasikan secara sama oleh responden. Keempat, Metode Servqual memenuhi kriteria parsimony, karena hanya terdiri dari 22 item. Kelima, metode Servqual memiliki prosedur analisis baku yang memudahkan interpretasi hasil. Menurut Yogiyanto (2016), survey merupakan metode pengumpulan data primer dengan memberikan pertanyaan-pertanyaan kepada responden secara tertulis dan tanpa komunikasi secara langsung. Survey seringkali menggunakan kuesioner sehingga survey jenis ini sering disebut survey kuesioner. Jenis survey digolongkan menjadi beberapa kelompok yaitu mail survey, group survey, pick up survey, computer-delivered survey dan intercept studies.

Menurut Jogiyanto (2016), terdapat empat macam tipe data untuk dasar dari skala yaitu nominal, ordinal, interval dan rasio. Terdapat 2 macam skala yaitu skala rating dan skala ranking. Penelitian ini menggunakan skala Likert. Skala Likert termasuk dalam jenis skala ranking dengan tipe data interval.

Pengukuran kualitas layanan model Servqual yang disusun dalam pernyataan pernyataan dalam skala Likert, dari 1 (Sangat Tidak Setuju) - 5 (Sangat Setuju) yang diberikan konsumen dalam setiap pertanyaan yang berkaitan dengan ekspetasi dan persepsi. Skor Servqual dapat dihitung dengan rumus berikut (Zeithaml, et al., 1990) : Skor Servqual $=$ Skor Persepsi - Skor Ekpetasi.

Persepsi (P) diartikan sebagai keyakinan konsumen terhadap pelayanan yang diterima dan dialami. Sedangkan untuk Ekspetasi (E) di rumuskan sebagai hasrat atau keinginan konsumen, yaitu apa yang mereka rasakan harus ditawarkan penyedia layanan. Parasuraman,et al dalam Service Management (Tjiptono, 2012)

Perhitungan nilai Servqual dilakukan dengan cara sebagai berikut :

1. Untuk mengetahui jumlah bobot jawaban pertanyaan ekspektasi pelayanan (Ismawati, 2013):

Keterangan :

$$
\sum \mathrm{yi}=\left(\sum \mathrm{Y} 1 \mathrm{x} 1\right)+\left(\sum \mathrm{Y} 2 \mathrm{x} 2\right)+\left(\sum \mathrm{Y} 3 \mathrm{x} 3\right)+\left(\sum \mathrm{Y} 4 \mathrm{x} 4\right)+\left(\sum \mathrm{Y} 5 \mathrm{x} 5\right)
$$

$\sum y i$ : Jumlah bobot jawaban pertanyaan

$\sum Y 1$ : jumlah orang yang memilih sangat tidak setuju

$\sum Y 2$ : jumlah orang yang memilih tidak setuju

$\sum Y 3$ : jumlah orang yang memilih netral 
$\sum Y 4:$ jumlah orang yang memilih setuju

$\sum Y 5$ : jumlah orang yang memilih sangat setuju

$1,2,3,4,5$ : Skor Skala Likert

Untuk mengetahui skor ekspektasi/harapan atau jumlah rata - rata dari jawaban responden kuesioner ekspektasi/harapan dalam menggunakan rumus sebagai berikut :

Keterangan :

$$
\mathrm{Yi}=\Sigma y i / \mathrm{n}
$$

Yi : rata - rata jawaban responden harapan/ekspektasi

$\sum y i$ : Jumlah bobot jawaban pertanyaan harapan/ekspektasi

$\mathrm{n}$ : Jumlah responden

2. Untuk mengetahui jumlah bobot jawaban pertanyaaan persepsi pelayanan (Ismawati, 2013):

Keterangan :

$$
\sum \mathrm{xi}=\left(\sum \mathrm{X} 1 \mathrm{x} 1\right)+\left(\sum \mathrm{X} 2 \mathrm{x} 2\right)+\left(\sum \mathrm{X} 3 \mathrm{x} 3\right)+\left(\sum \mathrm{X} 4 \mathrm{x} 4\right)+\left(\sum \mathrm{X} 5 \mathrm{x} 5\right)
$$

$\sum x i$ : Jumlah bobot jawaban pertanyaan

$\sum X 1$ : jumlah orang yang memilih sangat tidak puas

$\sum \mathrm{X} 2$ : jumlah orang yang memilih tidak puas

$\sum X 3$ : jumlah orang yang memilih netral

$\sum X 4$ : jumlah orang yang memilih puas

$\sum \mathrm{X} 5$ : jumlah orang yang memilih sangat puas

1,2,3,4,5 : Skor Skala Likert

Untuk mengetahui skor persepsi atau jumlah rata - rata dari jawaban responden kuesioner persepsi dalam menggunakan rumus sebagai berikut:

Keterangan :

$$
\mathrm{Xi}=\Sigma x i / \mathrm{n}
$$

$\mathrm{Xi}$ : rata - rata jawaban responden persepsi

$\sum x i$ : Jumlah bobot jawaban pertanyaan persepsi

$\mathrm{n}$ : Jumlah responden

Menurut Rangkuti (2008) konsep IPA berasal dari konsep Service Quality (SERVQUAL) yang mengutamakan tingkat kepentingan pelanggan dimana proses pengukuran dalam kaitannya dengan apa yang seharusnya dikerjakan oleh perusahaan untuk menghasilkan produk, atau jasa mutu tinggi. Tjiptono (2008) menambahkan IPA bermanfaat sebagai pedoman dalam mengalokasikan sumber daya organisasi terbatas pada bidangbidang spesifik, dimana perbaikan kinerja besar dapat berdampak pada kepuasan pelanggan total. Matriks IPA juga menunjukkan atribut tertentu yang perlu dipertahankan dan aspekaspek yang perlu dikurangi prioritasnya.

Pengukuran kepuasan pelanggan tidak selalu menggunakan Servqual, Anggraini dkk (2015) melakukan penelitian kepuasan pelanggan dengan atribut kepuasan yang diturunkan dari bauran pemasaran 7P (price, product, promotion, place, people, process, physical evidence)

Menurut Rangkuti (2008) dengan adanya berbagai persepsi tingkat kepentingan pelanggan, perusahaan dapat merumuskan tingkat kepentingan paling dominan. Tujuan utama menggunakan konsep tingkat kepentingan pelanggan, perusahaan dapat mengetahui persepsi yang lebih jelas mengenai pentingnya atribut oleh pelanggan. Analisis Importance dan Performance Matrix terdiri dari empat (4) kuadran sebagai berikut : 


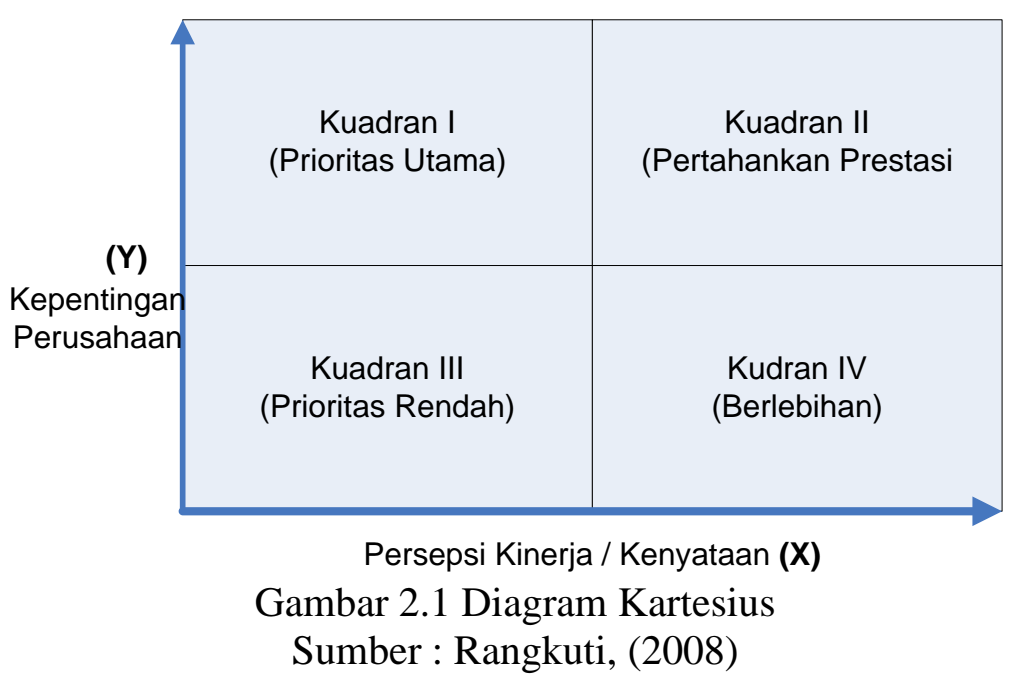

Customer Satisfaction Index (CSI) merupakan metode yang mengukur kepuasan konsumen berdasarkan atribut yang relevan dengan objek yang di teliti. Dalam penelitian ini CSI digunakan untuk mengetahui tingkat kepuasan secara menyeluruh dengan mempertimbangkan tingkat kepentingan atribut - atribut yang di ukur. Pada perhitungan CSI terdapat lima langkah pengukuran antara lain adalah (Aritonang, 2005) :

1. Mean Importance Satisfaction (MIS) Nilai ini berasal dari rata-rata kepentingan setiap atribut, dapat dihitung dengan rumus :

$$
\mathrm{MIS}=\frac{\text { jumlah nilai kepentingan }}{n} .
$$

2. Mean Satisfaction Score (MSS) Nilai ini berasal dari rata-rata nilai kinerja setiap atribut, dapat dihitung dengan cara sebagai berikut :

$$
M S S=\frac{\text { Jumlah nilai kinerja }}{n}
$$

3. Weight Factors (WF) Nilai ini berasal dari nilai MIS dibagi dengan total keseluruhan atribut MIS, dihitung dengan cara sebagai berikut : $W F=\frac{\text { nilai } M I S}{\text { total } M I S}$

4. Weight Score (WS) Nilai ini di ketahui dari perkalian antara WF setiap atribut dengan MSS

\section{Customer Satisfaction Index (CSI)}

$$
\mathrm{WS}=\mathrm{WF} \times \mathrm{MSS}
$$

$$
\text { CSI }=\frac{\text { Total } W S}{5} \times 100 \%
$$

Menghitung customer satisfaction index (indeks kepuasan pelanggan), yaitu weighted total dibagi skala maksimal yang digunakan (skala maksimal 5), lalu dikalikan $100 \%$. Tingkat kepuasan responden secara menyeluruh dapat dilihat dari kriteria tingkat kepuasan pelanggan. CSI memberikan data yang jelas mengenai tingkat kepuasan pelanggan sehingga pada satuan waktu tertentu dapat melakukan evaluasi secara berkala untuk memperbaiki apa yang kurang dan meningkatkan pelayanan yang dinilai customer adalah sebuah nilai lebih. 
Tabel 2.1 Customer Satisfaction Index (CSI)

\begin{tabular}{cccc}
\hline \multirow{2}{*}{ Atribut } & Kepentingan $(\mathrm{I})$ & Kepuasan $(\mathrm{P})$ & Skor $(\mathrm{S})$ \\
\cline { 2 - 4 } & Skala 1-5 & Skala 1-5 & $(\mathrm{S})=(\mathrm{I}) \times(\mathrm{P})$ \\
\hline & & & \\
\hline Skor Total & Total $(\mathrm{I})=(\mathrm{Y})$ & & Total $(\mathrm{S})=(\mathrm{T})$ \\
\hline
\end{tabular}

Perhitungan keseluruhan CSI menurut Bhote (1996) diilustrasikan pada tabel 2.1. Nilai rata-rata pada kolom kepentingan (I) dijumlahkan sehingga diperoleh $Y$ dan juga hasil kali I dengan P pada kolom skor (S) dijumlahkan dan diperoleh T. CSI diperoleh dari perhitungan (T/5Y) x $100 \%$.

Nilai 5 (pada 5Y) adalah nilai maksimum yang digunakan pada skala pengukuran. CSI dihitung dengan rumus:

Keterangan :

$$
\mathrm{CSI}=\frac{\mathrm{T}}{5 \mathrm{Y}} \times 100 \%
$$

$\mathrm{T}=$ Nilai Total Dari CSI

5 = Nilai Maksimum Pada Skala Pengukuran

$\mathrm{Y} \quad=$ Nilai Total Dari Kolom Harapan

Untuk mencari nilai CSI nilai Weight Score yang di dapat dibagi 5 yang merupakan skala yang digunakan pada pernelitian ini. Pada penelititan ini digunakan 5 skala dengan rentang adalah $20 \%$ berdasarkan skala ini maka kriteria kepuasan yang digunakan adalah (Fitriyanto, 2018) : $0 \%-20 \%=$ Sangat Tidak Puas, $21 \%-40 \%=$ Tidak Puas, $41 \%-60 \%=$ Cukup Puas/Sedikit Puas, $61 \%-80 \%=$ Puas, $81 \%-100 \%=$ Sangat Puas

\subsection{Penyusunan instrument penelitian dan penetapan sampel.}

Penyusunan kuesioner dilakukan dengan cara terlebih dahulu melakukan survey pendahuluan untuk mengetahui atribut-atribut di masing-masing dimensi Servqual. Atribut yang termasuk dalam dimensi Atribut yang termasuk dalam dimensi tangible Atribut yang termasuk dalam dimensi tangible (bukti nyata) sebanyak 12 atribut yaitu jumlah kasir yang mencukupi dan antrian yang pendek (Q1), tempat parkir yang luas $(\mathrm{Q} 2)$, suhu di dalam minimarket yang nyaman (Q3), penataan barang yang rapi (Q4), kondisi minimarket sangat bersih (Q5), pembayaran bisa menggunakan kartu debit (Q6), terdapat petunjuk lokasi barang (Q7), fasilitas keranjang belanja yang cukup (Q8), fasilitas duduk di depan minimarket (Q9), kelengkapan berbagai macam jenis produk (Q10), fasilitas CCTV di area parkir (Q11) dan fasilitas toilet yang bersih (Q12). Atribut yang termasuk dalam dimensi reliable (kehandalan) sebanyak 8 atribut : harga barang yang tercantum sesuai dengan harga yang di kasir (Q13), harga yang standar untuk minimarket yang sekelas atau selevel (Q4), ketersediaan barang selalu terjaga (Q15), kemudahan di dalam pembayaran (Q16), dapat melakukan pembayaran transaksi secara online (Q17), tata letak barang yang baik (Q18), sering diadakan promo produk dan harga (Q19), pegawai yang ramah, sopan, tertib dan rapi (Q20). Atribut yang termasuk dalam dimensi responsiveness (daya tanggap) sebanyak 3 atribut yaitu : karyawan cepat dan tepat dalam melayani konsumen dan menanggapi complain (Q21), kesiapan konsumen dalam membantu konsumen ketika dibutuhkan (Q22), kemampuan karyawan dalam memenuhi kebutuhan spesifik karyawan (Q23). Atribut 
yang termasuk dalam dimensi assurances (jaminan) sebanyak 5 atribut yaitu barang terjamin kehalalannya dan kualitasnya (tidak berkarat, kadaluarsa, rusak) (Q24), jaminan komunikasi yang baik antara karyawan dan konsumen (Q25), tempat parkir yang aman (Q26), keamanan saat menggunakan fasilitas (Q27) dan keamanan saat berbelanja (Q28), Sedangkan atribut yang termasuk dalam dimensi empathy (empati) sebanyak 1 atribut yaitu keluhan dan saran ditanggapi dengan serius (Q29). Secara total terdapat 29 atribut Servqual yang akan dipakai untuk mengetahui tingkat kepuasan pelanggan.

Atribut-atribut tersebut akan dipergunakan untuk mengukur tingkat kepentingan / harapan dan tingkat kepuasan / kinerja. diukur dengan menggunakan skala Likert dari 1 hingga 5. Tingkat kepentingan / harapan diukur dengan skala Likert yang terdiri dari : 1 = Sangat Tidak Setuju, 2 = Tidak Setuju, $3=$ Netral, $4=$ Setuju dan 5 = Sangat Setuju. Tingkat kepuasan / kinerja diukur dengan skala Likert yang terdiri dari : $1=$ Sangat Tidak Puas, $2=$ Tidak Puas, $3=$ Netral, $4=$ Puas dan 5 = Sangat Puas (Jonathan, 2006 di dalam Budhi \& Sumiari, 2017).

Sampel dalam penelitian ini ditetapkan dengan rumus Slovin. Populasi dalam penelitian ini adalah seluruh pelanggan atau pengunjung Minimarket SK, baik yang sudah pernah mengunjungi maupun yang baru pertama kali belanja. Jumlah populasi pada penelitian ini selama 1 bulan sejak 8 Mei 2019 - 8 Juli 2019 sebanyak 1.900 pelanggan. Dengan rata-rata pelanggan per bulan sebanyak 950 pelanggan.

Untuk menentukan jumlah minimal sampel, digunakan pendapat dari Slovin yaitu (Umar, 2005 di dalam Budhi \& Sumiari, 2017) :

$$
\begin{gathered}
\mathrm{n}=\frac{N}{1+N(e)^{2}} \\
=\frac{950}{1+950 \cdot(0,1)^{2}} \\
=90,47
\end{gathered}
$$

Keterangan :

$\mathrm{n}=$ Sampel

$\mathrm{N}=$ populasi Sampel

$\mathrm{e}=$ error (kesalahan) $10 \%$

Agar mendapatkan hasil data yang lebih akurat, maka jumlah responden yang akan dijadikan sampel, digenapkan menjadi 100 responden.

\subsection{Uji Kuesioner}

Untuk menentukan kelayakan kuesioner maka dilakukan uji validitas dan uji reliabilitas. Syarat alat ukur bersifat valid adalah apabila nilai $r$ hitung lebih besar dari nilai $r$ tabel. Uji validitas dilakukan untuk mengetahui keakuratan dari masing masing pertanyaan yang disebarkan. Dalam penelitian ini, nilai $\mathrm{r}$ hitung diketahui dengan menggunakan software pembantu. Sedangkan nilai $r$ tabel diketahui dari tabel $r$ statistika. Nilai $r$ tabel pada penelitian ini menggunakan tingkat signifikansi $5 \%$ untuk uji 2 arah adalah 0,1966 .

Uji reliabilitas dilakukan untuk mengetahui apakah butir-butir pertanyaan yang terdapat dalam kuesioner yang digunakan sebagai alat pengumpul data betul betul reliabel dalam arti bahwa alat pengumpul data tersebut tetap konsisten untuk mengukur suatu 29 gejala yang sama dari beberapa responden. Penelitian ini menggunakan metode Cronbach Alpha untuk mengukur reliabilitas. Alat ukur dikatakan reliabel jika memiliki koefisien alpha lebih besar dari 0,70. Kuisioner di katakan reliabel jika $r$ hasil lebih besar dari $r$ tabel ( $r$ hasil $>0,70)$. Semakin besar 
nilai alpha Cronbach, maka semakin tinggi tingkat reliabilitas penelitian yang dilakukan.

Wahyu (2004) menyatakan bahwa pengujian relibilitas digunakan untuk mengetahui sejauh mana pengukur itu dapat memberikan hasil yang relatif sama. Pengujian relibilitas ini menggunakan koefisien alpha dari cronbanch (Hadi dalam Wahyu, 2004)

Keterangan :

$$
r=\left(\frac{M}{M-1}\right)\left(\frac{V_{y}-V_{x}}{V_{y}}\right)
$$

$\mathrm{r}=$ Nilai reliabilitas

$\mathrm{M}=$ jumlah butir pertanyaan

$\mathrm{Vx}=$ Variansi butir-butir

$\mathrm{Vy}=$ Variansi total

Menurut Uyanto dalam Rosyidah (2015) skala pengukuran yang reliabel sebaiknya memiliki Cronbach Alpha $\geq 0,7$. Kriteria instrumen reabilitas :

1. $\alpha<0,2: \quad$ Instrumen tidak reliabel

2. $0,2 \leq \alpha<0,4$ : Reliabilitas instrumen kecil

3. $0,4 \leq \alpha<0,7$ : Instrumen cukup reliabel

4. $\quad 0,7 \leq \alpha<0,9$ : Instrumen reliabel

5. $0,9 \leq \alpha<1,0$ : Instrumen sangat reliabel

6. $\alpha=1,0$ : Reliabilitas instrumen sempurna

\section{HASIL DAN PEMBAHASAN}

Syahru Aryansyah, Presiden Direktur PT Hydro Perdana Retailindo dalam situs https://industri.kontan.co.id/news/tahun-ini-hydro-perdana-targetkan-punya500-gerai-sodaqo-mart-dan-212-mart_mengatakan bahwa PT HPR di tahun 2018 ke depan menargetkan akan punya 500 gerai, sedangkan tahun depan akan buka 1.500 gerai dan tahun 2022 mendatang itu juga insyaAllah akan punya 8.000 gerai (Dwijayanto, 2018).

Hasil uji validitas dan reliabilitas menunjukkan bahwa seluruh atribut valid dan reliable. Seperti yang tercantum dalam tabel dibawah ini :

Tabel 3.1 Hasil Uji Validitas

\begin{tabular}{|c|c|c|c|c|c|}
\hline \multirow{2}{*}{\multicolumn{2}{|c|}{ Pernyataan }} & \multicolumn{2}{|c|}{ Nilai korelasi } & \multirow{2}{*}{$\begin{array}{c}r \text { tabel } \\
100 ; 0,1966\end{array}$} & \multirow{2}{*}{ Keterangan } \\
\hline & & Kepentingan & kinerja & & \\
\hline \multirow{12}{*}{ Tangibel } & Q1 & 0,742 & 0,26 & 0,1966 & Valid \\
\hline & $\mathrm{Q} 2$ & 0,481 & 0,693 & 0,1966 & Valid \\
\hline & Q3 & 0,268 & 0,41 & 0,1966 & Valid \\
\hline & $\mathrm{Q} 4$ & 0,65 & 0,475 & 0,1966 & Valid \\
\hline & Q5 & 0,687 & 0,317 & 0,1966 & Valid \\
\hline & Q6 & 0,652 & 0,254 & 0,1966 & Valid \\
\hline & Q7 & 0,502 & 0,79 & 0,1966 & Valid \\
\hline & Q8 & 0,477 & 0,773 & 0,1966 & Valid \\
\hline & Q9 & 0,748 & 0,773 & 0,1966 & Valid \\
\hline & Q10 & 0,268 & 0,228 & 0,1966 & Valid \\
\hline & Q11 & 0,552 & 0,7 & 0,1966 & Valid \\
\hline & Q12 & 0,268 & 0,476 & 0,1966 & Valid \\
\hline
\end{tabular}




\begin{tabular}{|c|c|c|c|c|c|}
\hline \multirow{2}{*}{ Pernyataan } & & \multicolumn{2}{|c|}{ Nilai korelasi } & \multirow{2}{*}{$\begin{array}{c}r \text { tabel } \\
100 ; 0,1966\end{array}$} & \multirow{2}{*}{ Keterangan } \\
\hline & & Kepentingan & kinerja & & \\
\hline \multirow{8}{*}{ Reliability } & Q13 & 0,287 & 0,476 & 0,1966 & Valid \\
\hline & Q14 & 0,268 & 0,314 & 0,1966 & Valid \\
\hline & Q15 & 0,748 & 0,773 & 0,1966 & Valid \\
\hline & Q16 & 0,545 & 0,254 & 0,1966 & Valid \\
\hline & Q17 & 0,748 & 0,254 & 0,1966 & Valid \\
\hline & Q18 & 0,384 & 0,749 & 0,1966 & Valid \\
\hline & Q19 & 0,207 & 0,454 & 0,1966 & Valid \\
\hline & Q20 & 0,567 & 0,219 & 0,1966 & Valid \\
\hline \multirow{3}{*}{ Responsiveness } & Q21 & 0,481 & 0,697 & 0,1966 & Valid \\
\hline & Q22 & 0,493 & 0,715 & 0,1966 & Valid \\
\hline & Q23 & 0,306 & 0,254 & 0,1966 & Valid \\
\hline \multirow{5}{*}{ Assurance } & Q24 & 0,253 & 0,332 & 0,1966 & Valid \\
\hline & Q25 & 0,726 & 0,773 & 0,1966 & Valid \\
\hline & Q26 & 0,703 & 0,304 & 0,1966 & Valid \\
\hline & Q27 & 0,748 & 0,267 & 0,1966 & Valid \\
\hline & Q28 & 0,538 & 0,73 & 0,1966 & Valid \\
\hline Emphaty & Q29 & 0,371 & 0,254 & 0,1966 & Valid \\
\hline
\end{tabular}

Berdasarkan tabel hasil uji validitas diatas dapat diketahui bahwa semua item pernyataan/Indikator dimensi Tangibel, Reliability, Responsiveness, Assurance, Emphaty, dinyatakan valid karena dari hasil korelasi antara hasil jawaban responden pada tiap item pernyataan/indikator dengan total skor didapat hasil yang signifikan, yaitu korelasi > r tabel $(0,1966)$.

Tabel 3.2 Hasil Uji Reliabilitas

\begin{tabular}{ccc}
\hline \multicolumn{2}{c}{ Alpha Cronbach } & \multirow{2}{*}{ Keterangan } \\
\cline { 1 - 2 } Kepentingan & Kinerja & \\
\hline $0,741>0,7$ & $0,738>0,7$ & Reliabel \\
\hline
\end{tabular}

Hasil rekapitulasi data menunjukkan adanya kesenjangan antara tingkat harapan / kepentingan terhadap tingkat kepuasan / kinerja :

Tabel 3.3 Kesenjangan antara Tingkat Kinerja dan Tingkat Kepentingan

\begin{tabular}{|c|c|c|c|c|c|c|}
\hline \multirow{2}{*}{ Simbol } & \multicolumn{2}{|c|}{ Kinerja } & \multirow{2}{*}{ Simbol } & \multicolumn{2}{|c|}{ Kepentingan } & \multirow{2}{*}{$\begin{array}{c}\text { Kesenjangan } \\
\text { (Q) }\end{array}$} \\
\hline & Jumlah & Rata-rata & & Jumlah & Rata-rata & \\
\hline$x 1$ & 326 & 3,26 & y1 & 364 & 3,64 & $-0,38$ \\
\hline$\times 2$ & 233 & 2,33 & $y 2$ & 265 & 2,65 & $-0,32$ \\
\hline$x 3$ & 435 & 4,35 & y3 & 458 & 4,58 & $-0,23$ \\
\hline$x 4$ & 436 & 4,36 & y4 & 368 & 3,68 & 0,68 \\
\hline$x 5$ & 325 & 3,25 & y5 & 371 & 3,71 & $-0,46$ \\
\hline$x 6$ & 139 & 1,39 & y6 & 369 & 3,69 & $-2,3$ \\
\hline$x 7$ & 235 & 2,35 & y7 & 262 & 2,62 & $-0,27$ \\
\hline$x 8$ & 240 & 2,4 & y8 & 264 & 2,64 & $-0,24$ \\
\hline$x 9$ & 240 & 2,4 & y9 & 360 & 3,6 & $-1,2$ \\
\hline
\end{tabular}




\begin{tabular}{|c|c|c|c|c|c|c|}
\hline \multirow{2}{*}{ Simbol } & \multicolumn{2}{|c|}{ Kinerja } & \multirow{2}{*}{ Simbol } & \multicolumn{2}{|c|}{ Kepentingan } & \multirow{2}{*}{$\begin{array}{c}\text { Kesenjangan } \\
\text { (Q) }\end{array}$} \\
\hline & Jumlah & Rata-rata & & Jumlah & Rata-rata & \\
\hline$x 10$ & 349 & 3,49 & y10 & 458 & 4,58 & $-1,09$ \\
\hline $\mathrm{x} 11$ & 235 & 2,35 & y11 & 261 & 2,61 & $-0,26$ \\
\hline $\mathrm{x} 12$ & 443 & 4,43 & $\mathrm{y} 12$ & 458 & 4,58 & $-0,15$ \\
\hline $\mathrm{x} 13$ & 443 & 4,43 & y13 & 455 & 4,55 & $-0,12$ \\
\hline $\mathrm{x} 14$ & 461 & 4,61 & y14 & 458 & 4,58 & 0,03 \\
\hline$\times 15$ & 240 & 2,4 & y15 & 360 & 3,6 & $-1,2$ \\
\hline $\mathrm{x} 16$ & 327 & 3,27 & y16 & 376 & 3,76 & $-0,49$ \\
\hline $\mathrm{x} 17$ & 139 & 1,39 & y17 & 360 & 3,6 & $-2,21$ \\
\hline $\mathrm{x} 18$ & 235 & 2,35 & $\mathrm{y} 18$ & 267 & 2,67 & $-0,32$ \\
\hline $\mathrm{x} 19$ & 440 & 4,4 & y19 & 452 & 4,52 & $-0,12$ \\
\hline$x 20$ & 369 & 3,69 & y20 & 341 & 3,41 & 0,28 \\
\hline$\times 21$ & 231 & 2,31 & y21 & 261 & 2,61 & $-0,3$ \\
\hline$x 22$ & 234 & 2,34 & y22 & 260 & 2,6 & $-0,26$ \\
\hline$\times 23$ & 139 & 1,39 & $\mathrm{y} 23$ & 162 & 1,62 & $-0,23$ \\
\hline$\times 24$ & 463 & 4,63 & y24 & 443 & 4,43 & 0,2 \\
\hline$x 25$ & 240 & 2,4 & $y 25$ & 364 & 3,64 & $-1,24$ \\
\hline$\times 26$ & 328 & 3,28 & y26 & 365 & 3,65 & $-0,37$ \\
\hline$x 27$ & 330 & 3,3 & y27 & 360 & 3,6 & $-0,3$ \\
\hline$x 28$ & 238 & 2,38 & $y 28$ & 258 & 2,58 & $-0,2$ \\
\hline x29 & 139 & 1,39 & y29 & 245 & 2,45 & $-1,06$ \\
\hline
\end{tabular}

Nilai-nilai yang yang telah dianalisa diatas kemudian dipetakan ke kuadran IPA sebagaimana digambarkan pada gambar dibawah ini :

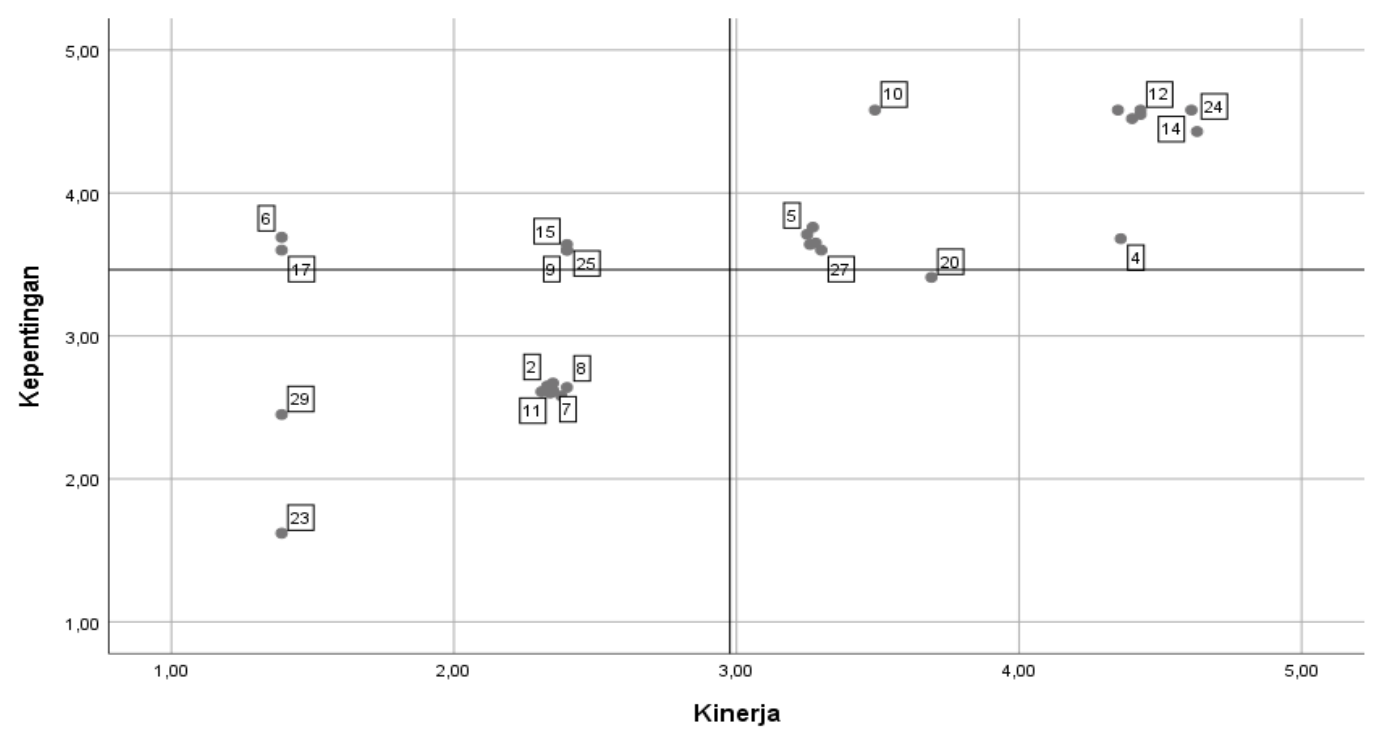

Gambar 3.1. Diagram IPA

\section{Kuadran I}

Kuadran I merupakan dimana berisi atribut dengan tingkat kepentingan tinggi dan kepuasan yang diperoleh masih rendah sehingga menjadi prioritas utama untuk diperbaiki, adapun atribut-atribut yang termasuk dalam kuadran I berturut-turut adalah 6, 9, 15, 17, dan 25. 


\section{Kuadran II}

Kuadran II merupakan kuadran yang didalamnya berisi atribut yang memiliki tingkat kepentingan tinggi dan nilai kepuasan juga tinggi sehingga Minimarket SK wajib mempertahankan atribut yang ada dalam kuadran II, adapun atribut yang perlu dipertahan dan termasuk dalam kuadran II berturut-turut adalah 1, 3, 4, 5, 10, 12, 13, 14, 16, 19, 24, 26, dan 27. jika dilihat dan dibandingkan terdapat beberapa atribut yang termasuk dalam kuadran II tetapi memiliki nilai gap yang tergolong tinggi, hal ini dikarenakan nilai rata-rata kepentingan memiliki nilai lebih tinggi dari nilai kepuasan konsumen namun jika di ambil garis lurus kedua nilai tersebut memiliki titik temu pada lokasi kuadran II.

\section{Kuadran III}

Kuadran III merupakan kuadran yang berisi atribut yang memiliki tingkat kepentingan rendah dibanding nilai rata-rata dan dan nilai tingkat kepuasan juga lebih rendah dari nilai rata-rata. Adapun atribut yang termasuk dalam Kuadran ini berturut-turut adalah $2,7,8,11,18,21,22,23,28$, dan 29 . Pada kuadran III terdapat gap yang memiliki nilai tergolong tinggi hal ini dikarenakan nilai rata - rata dari atribut kepentingan dan kepuasan tidak melebihi nilai rata-rata dari seluruh atribut namun selisih kepentingan dan kepuasan dari atribut cukup banyak.

\section{Kuadran IV}

Kuadran IV merupakan atribut yang memiliki nilai tingkat kepuasan tinggi dan namun atribut dalam Kuadran ini memiliki nilai kepentingan rendah. Dalam penelitian ini, atribut yang berada di kuadran ini hanya atribut nomor 20 , yang berarti Minimarket SK memberikan pelayanan yang berlebihan kepada konsumen pada atribut ini.

Tabel 3.4 Customer Satisfaction Index (CSI)

\begin{tabular}{|c|c|c|c|c|c|c|c|}
\hline \multirow{2}{*}{ NO } & \multirow{2}{*}{ Pernyataan } & \multicolumn{2}{|c|}{$\begin{array}{c}\text { Tingkat } \\
\text { Kepentingan }\end{array}$} & \multicolumn{2}{|c|}{ Tingkat Kinerja } & \multirow{2}{*}{ WF } & \multirow{2}{*}{ WS } \\
\hline & & Jumlah & $\begin{array}{l}\text { Nilai } \\
\text { MIS }\end{array}$ & Jumlah & $\begin{array}{l}\text { Nilai } \\
\text { MSS }\end{array}$ & & \\
\hline 1 & $\begin{array}{l}\text { Jumlah kasir yang } \\
\text { mencukupi dan } \\
\text { antrian pendek }\end{array}$ & 364 & 3,64 & 326 & 3,26 & 0,03533 & 0,115 \\
\hline 2 & $\begin{array}{l}\text { Tempat parkir yang } \\
\text { luas }\end{array}$ & 265 & 2,65 & 233 & 2,33 & 0,02572 & 0,06 \\
\hline 3 & $\begin{array}{l}\text { Suhu didalam } \\
\text { minimarket yang } \\
\text { nyaman }\end{array}$ & 458 & 4,58 & 435 & 4,35 & 0,04445 & 0,193 \\
\hline 4 & $\begin{array}{l}\text { Penataan barangnya } \\
\text { rapi }\end{array}$ & 368 & 3,68 & 436 & 4,36 & 0,03572 & 0,156 \\
\hline 5 & $\begin{array}{l}\text { Kondisi minimarket } \\
\text { SK sangat bersih }\end{array}$ & 371 & 3,71 & 325 & 3,25 & 0,03601 & 0,117 \\
\hline 6 & $\begin{array}{l}\text { Pembayaran bisa } \\
\text { menggunakan kartu } \\
\text { debit }\end{array}$ & 369 & 3,69 & 139 & 1,39 & 0,03581 & 0,05 \\
\hline 7 & $\begin{array}{l}\text { terdapat petujuk } \\
\text { lokasi barang }\end{array}$ & 262 & 2,62 & 235 & 2,35 & 0,02543 & 0,06 \\
\hline 8 & $\begin{array}{l}\text { fasilitas keranjang } \\
\text { belanja yang cukup }\end{array}$ & 264 & 2,64 & 240 & 2,4 & 0,02562 & 0,061 \\
\hline 9 & $\begin{array}{l}\text { fasilitas duduk } \\
\text { didepan minimarket }\end{array}$ & 360 & 3,6 & 240 & 2,4 & 0,03494 & 0,084 \\
\hline 10 & Kelengkapan & 458 & 4,58 & 349 & 3,49 & 0,04445 & 0,155 \\
\hline
\end{tabular}




\begin{tabular}{|c|c|c|c|c|c|c|c|}
\hline \multirow{2}{*}{ NO } & \multirow{2}{*}{ Pernyataan } & \multicolumn{2}{|c|}{$\begin{array}{c}\text { Tingkat } \\
\text { Kepentingan }\end{array}$} & \multicolumn{2}{|c|}{ Tingkat Kinerja } & \multirow{2}{*}{ WF } & \multirow{2}{*}{ WS } \\
\hline & & Jumlah & $\begin{array}{l}\text { Nilai } \\
\text { MIS }\end{array}$ & Jumlah & $\begin{array}{l}\text { Nilai } \\
\text { MSS }\end{array}$ & & \\
\hline & $\begin{array}{l}\text { berbagai macam } \\
\text { jenis produk }\end{array}$ & & & & & & \\
\hline 11 & $\begin{array}{l}\text { fasilitas CCTV di } \\
\text { area parkir }\end{array}$ & 261 & 2,61 & 235 & 2,35 & 0,02533 & 0,06 \\
\hline 12 & $\begin{array}{l}\text { fasilitas toilet yang } \\
\text { bersih }\end{array}$ & 458 & 4,58 & 443 & 4,43 & 0,04445 & 0,197 \\
\hline 13 & $\begin{array}{l}\text { Harga barang yang } \\
\text { tercantum sesuai } \\
\text { dengan harga yang di } \\
\text { kasir }\end{array}$ & 455 & 4,55 & 443 & 4,43 & 0,04416 & 0,196 \\
\hline 14 & $\begin{array}{l}\text { Harga yang standar } \\
\text { untuk minimarket } \\
\text { sekelas atau selevel }\end{array}$ & 458 & 4,58 & 461 & 4,61 & 0,04445 & 0,205 \\
\hline 15 & $\begin{array}{l}\text { Ketersediaan barang } \\
\text { selalu terjaga }\end{array}$ & 360 & 3,6 & 240 & 2,4 & 0,03494 & 0,084 \\
\hline 16 & $\begin{array}{l}\text { Kemudahan dalam } \\
\text { pembayaran }\end{array}$ & 376 & 3,76 & 327 & 3,27 & 0,03649 & 0,119 \\
\hline 17 & $\begin{array}{l}\text { dapat melakukan } \\
\text { pembayaran } \\
\text { transaksi belanja } \\
\text { online }\end{array}$ & 360 & 3,6 & 139 & 1,39 & 0,03494 & 0,049 \\
\hline 18 & $\begin{array}{l}\text { tata letak barang } \\
\text { yang baik }\end{array}$ & 267 & 2,67 & 235 & 2,35 & 0,02591 & 0,061 \\
\hline 19 & $\begin{array}{l}\text { sering adanya promo } \\
\text { produk dan harga }\end{array}$ & 452 & 4,52 & 440 & 4,4 & 0,04387 & 0,193 \\
\hline 20 & $\begin{array}{l}\text { Pegawai yang ramah, } \\
\text { sopan, tertib, dan } \\
\text { rapi. }\end{array}$ & 341 & 3,41 & 369 & 3,69 & 0,0331 & 0,122 \\
\hline 21 & $\begin{array}{l}\text { Karyawan cepat dan } \\
\text { tepat dalam melayani } \\
\text { konsumen dan } \\
\text { menanggapi } \\
\text { komplain } \\
\end{array}$ & 261 & 2,61 & 231 & 2,31 & 0,02533 & 0,059 \\
\hline 22 & $\begin{array}{l}\text { Kesiapan konsumen } \\
\text { dalam membantu } \\
\text { konsumen ketika } \\
\text { dibutuhkan }\end{array}$ & 260 & 2,6 & 234 & 2,34 & 0,02524 & 0,059 \\
\hline 23 & $\begin{array}{l}\text { Kemampuan } \\
\text { karyawan dalam } \\
\text { memenuhi } \\
\text { kebutuhan spesifik } \\
\text { konsumen. }\end{array}$ & 162 & 1,62 & 139 & 1,39 & 0,01572 & 0,022 \\
\hline
\end{tabular}




\begin{tabular}{|c|c|c|c|c|c|c|c|}
\hline \multirow{2}{*}{ NO } & \multirow{2}{*}{ Pernyataan } & \multicolumn{2}{|c|}{$\begin{array}{c}\text { Tingkat } \\
\text { Kepentingan }\end{array}$} & \multicolumn{2}{|c|}{ Tingkat Kinerja } & \multirow{2}{*}{ WF } & \multirow{2}{*}{ WS } \\
\hline & & Jumlah & $\begin{array}{l}\text { Nilai } \\
\text { MIS }\end{array}$ & Jumlah & $\begin{array}{l}\text { Nilai } \\
\text { MSS }\end{array}$ & & \\
\hline 24 & $\begin{array}{l}\text { Barang terjamin } \\
\text { kehalalannya dan } \\
\text { kualitasnya (tidak } \\
\text { berkarat, } \\
\text { kadaluarsa, rusak.) }\end{array}$ & 443 & 4,43 & 463 & 4,63 & 0,043 & 0,199 \\
\hline 25 & $\begin{array}{l}\text { Jaminan komunikasi } \\
\text { yang baik antara } \\
\text { karyawan dan } \\
\text { konsumen }\end{array}$ & 364 & 3,64 & 240 & 2,4 & 0,03533 & 0,085 \\
\hline 26 & $\begin{array}{l}\text { tempat parkir yang } \\
\text { aman }\end{array}$ & 365 & 3,65 & 328 & 3,28 & 0,03543 & 0,116 \\
\hline 27 & $\begin{array}{l}\text { keamanan saat } \\
\text { menggunakan } \\
\text { fasilitas }\end{array}$ & 360 & 3,6 & 330 & 3,3 & 0,03494 & 0,115 \\
\hline 28 & $\begin{array}{l}\text { keamanan saat } \\
\text { berbelanja }\end{array}$ & 258 & 2,58 & 238 & 2,38 & 0,02504 & 0,06 \\
\hline \multirow[t]{2}{*}{29} & $\begin{array}{l}\text { Keluhan dan saran } \\
\text { ditanggapi dengan } \\
\text { serius. }\end{array}$ & 245 & 2,45 & 139 & 1,39 & 0,02378 & 0,033 \\
\hline & & $\begin{array}{l}\text { Total } \\
\text { MIS }\end{array}$ & 103,03 & & & $\begin{array}{l}\text { Total } \\
\text { WS }\end{array}$ & 3,143 \\
\hline
\end{tabular}

Pada penelititan ini digunakan 5 skala dengan rentang adalah $20 \%$ berdasarkan skala ini maka kriteria kepuasan yang digunakan adalah :

$0 \%-20 \%=$ Sangat Tidak Puas

$21 \%-40 \%=$ Tidak Puas

$41 \%-60 \%=$ Cukup Puas

$61 \%-80 \%=$ Puas

$81 \%-100 \%=$ Sangat Puas

$$
\begin{aligned}
& C S I= \frac{\text { Total } W S}{5} \times 100 \% \\
& C S I=\frac{3,143}{5} \times 100 \% \\
&=0,6286 \times 100 \% \\
&=62,86 \%
\end{aligned}
$$

Jadi diketahui dari tabel dan perhitungan CSI diatas bahwa nilai CSI kepuasan konsumen sebesar 62,86\% ini terdapat pada rentang $61 \%-80 \%$ dengan arti tingkat kepuasan konsumen "Puas"

Dari analisa perhitungan menggunakan IPA dan CSI terdapat beberapa hal yang bisa dianalisa. Hasil kuesioner Servqual (tabel 3.3) menunjukkan adanya 25 pernyataan $(86 \%)$ yang memiliki kesejangan negatif antara tingkat kinerja dan tingkat harapan/kepentingan. Artinya harapan/kepentingan dari pelanggan belum dipenuhi oleh kinerja layanan dari minimarket SK. Dari 29 pertanyaan hanya 4 
pertanyaan (14\%) yang nilai kesenjangannya bernilai positif. Pernyataan tersebut adalah pernyataan 4 (Penataan barangnya rapi), pernyataan 14 (Harga yang standar untuk minimarket sekelas atau selevel), Pernyataan 20 (Pegawai yang ramah, sopan, tertib, dan rapi) dan pernyataan 24 (Barang terjamin kehalalannya dan kualitasnya (tidak berkarat, kadaluarsa, rusak). Walaupun profile kesenjangan nilai kinerja dan nilai harapan seperti yang telah disebutkan namun secara keseluruhan, indeks kepuasan pelanggan sebesar $62,86 \%$. Sudah masuk dalam kriteria "puas" tapi masih pada nilai yang dekat dengan nilai terendah (61\%). Sehingga perlu dilakukan langkah-langkah perbaikan yang untuk meningkatkan indeks kepuasan pelanggan.

Untuk meningkatkan indeks kepuasan pelanggan maka tidak mungkin memperbaiki pernyataan yang memiliki nilai kesenjangan negatif dengan prosentase sebesar $86 \%$. Agar efektif, maka cukup menindaklanjuti pernyataan kesenjangan negatif yang ada di kuadran 1 pada diagram IPA (gambar 3.1). Kuadran I merupakan dimana berisi atribut dengan tingkat kepentingan tinggi dan kepuasan yang diperoleh masih rendah sehingga menjadi prioritas utama untuk diperbaiki, adapun atribut-atribut yang termasuk dalam kuadran I berturut-turut adalah 6 (Pembayaran bisa menggunakan kartu debit), 9 (fasilitas duduk didepan minimarket), 15 (Ketersediaan barang selalu terjaga), 17 (dapat melakukan pembayaran transaksi belanja online), dan 25 (Jaminan komunikasi yang baik antara karyawan dan konsumen). Dengan demikian manajemen minimarket SK perlu untuk memprorgamkan adanya layanan pembayaran menggunakan kartu debit), pengadaan fasilitas duduk di depan minimarket), menjaga ketersediaan barang selalu terjaga dan mengadakan layanan pembayaran transaksi belanja online.

\section{KESIMPULAN}

Berdasarkan perhitungan kesenjangan antara persepsi dan harapan diketahui beberapa atribut masih bernilai negatif yang berarti persepsi / kinerja lebih kecil dari harapan/kepentingan konsumen terhadap pelayanan yang ada di Minimarket SK. Atribut yang bernilai negatif tersebut tersebut dijadikan acuan sebagai penunjang dalam perbaikan. Semua atribut pada penelitian ini dijadikan penunjang dalam perbaikan terkecuali beberapa atribut yang bernilai positif. Atribut yang bernilai positif tersebut tidak dijadikan acuan sebagai dalam perbaikan karena persepsi konsumen terhadap kualitas pelayanan yang diberikan sudah melebihi harapan konsumen. Atribut yang tidak dijadikan acuan sebagai faktor penentu dalam perbaikan tersebut adalah : penataan barangnya rapi, harga yang standar untuk minimarket sekelas atau selevel, pegawai yang ramah, sopan tertib dan rapi, barang terjamin kehalalannya dan kualitasnya (tidak berkarat, kadaluarsa dan rusak). Berdasarkan analisa metode Importance Performance Index (IPA), berikut atribut yang harus diprioritaskan dalam perbaikan untuk meningkatkan kualitas pelayanan pada Minimarket SK : Pembayaran bisa menggunakan kartu debit, fasilitas duduk didepan minimarket, ketersediaan barang selalu terjaga, dapat melakukan pembayaran transaksi belanja online dan jaminan komunikasi yang baik antara karyawan dengan konsumen. Berdasarkan perhitungan indek kepuasan nilai Customer Satisfaction Index (CSI) Minimarket SK yang berada di Serang, Banten, diketahui masih berada pada rentang $61 \%$ - $80 \%$ yaitu $62,86 \%$ yang berarti secara keseluruhan konsumen masih merasa "puas" dengan pelayanan yang ada di Minimarket SK.

\section{DAFTAR PUSTAKA}

Aritonang, R.L, 2005, Kepuasan pelanggan, Jakarta : Gramedia 
Anggraini, Deoranto \& Ikasari, 2015, Analisis Persepsi Konsumen Menggunakan Metode Importance Performance Analysis dan Customer Satisfaction Index, Jurnal Industri Vol 4, No 2 halaman 74-81.

Astuty, 2014, Tingkat Kepuasan Pelanggan Ticketing : Analisis Tingkat Kepuasan Pelanggan Ticketing pada PT Trans Lintas Cakrawala Samarinda, eJournal Ilmu Administrasi Bisnis, 2014, 2 (1) : 1-4

Bhote, K.R., 1996, Beyond Customer Satisfaction to Customer Loyality: The Key to Great Profitability. New York: AMA Membership Publications Division, American Management Association.

Budhi \& Sumiari, 2017, Pengukuran Customer Satisfaction Index Terhadap Pelayanan di Century Gym, Jurnal Ilmiah SISFOTENIKA, Vol. 7, No. 1 Januari 2017

Dewi, Restuputri \& Sulaksmi, 2015, Analisis Kepuasan Pelanggan dengan Pendekatan Metode Customer Satisfaction Index dan Importance Performance Analysis, Seminar Teknologi dan Rekayasa (SENTRA) 2015, ISBN: 978-979796-238-6

Dwijayanto, Andy, 2018, Tahun ini Hydro Perdana targetkan punya 500 gerai Sodaqo mart dan 212 mart, [Internet]. Tersedia : https://industri.kontan.co.id/news/tahun-ini-hydro-perdana-targetkan-punya500-gerai-sodaqo-mart-dan-212-mart [03/08/2019]

Fitriyanto, M. A, 2018, “Analisis Tingkat Kepuasan Konsumen Terhadap Kualitas Layanan Dengan Metode Service Quality dan Importance Performance Analysis. (Studi kasus pada PT. Lion Superindo)." Skripsi. . Jakarta : Program Studi Teknik Industri Fakultas Teknologi Industri. Universitas Islam Indonesia Jakarta. Tidak Diterbitkan.

Ismawati, Intan, 2013, “Analisis Kepuasan Pelanggan dan Loyalitas Pelanggan Dealer Nissan Cabang Padjajaran ( Studi Kasus pada Dealer Nissan Cabang Padjajaran bogor.)" Skripsi. Bogor : Program Sarjana Alih Jenis Manajemen Departemen Manajemen Fakultas Ekonomi dan Manajemen. Institut Pertanian Bogor. Tidak Diterbitkan

Jogiyanto, 2016, Pedoman Survei Kuesioner : Mengembangkan Kuesioner, Mengatasi Bias dan Meningkatkan Respon, Fakultas Ekonomika dan Bisnis UGM

Kotler, Philip, 1998, Manajemen Pemasaran Analisis Perencanaan, Implementasi dan Kontrol. Jakarta : PT. Prenhallindo

Rangkuti, F, 2008, Measuring Customer Satisfaction Tehnik Mengukur dan Strategi Meningkatkan Kepuasan Pelanggan plus Analisis Kasus PLN-JP. Jakarta : PT. Gramedia Pustaka Utama

Rahmasari, Nurmalina \& Priatna, 2017, Analisis Sikap, Konsistensi dan Kepuasan pada The Kotak Ultrajaya : An Experimental Marketing Research on IPB Agribusiness Master of Science Students, Jurnal Forum Agribusiness, Vol. 7, No. 1, Maret 2017 
Rosyidah, H, et al., 2015, "Analisis Kualitas Pelayanan dengan Menggunakan Fuzzy Servqual. Kuadran IPA, dan Indeks PGCV.” Jurnal Gaussian. Vol.4. No.4, 885894.

Sangadji, et al, 2013, Perilaku Konsumen - Pendekatan Praktis disertai Himpunan Jurnal Penelitian. Yogyakarta: PT. ANDI

Sumaga, 2013, Analisis Kepuasan Pengguna Jasa Terhadap Penerapan Manajemen Rekayasa Konstruksi Profesional Ruko di Kawasan Business Park Kota Gorontalo, Jurnal Ilmiah Media Engineering Vol 3, No.1, Maret 2013.

Syukri, 2014, Penerapan Customer Satisfaction Index dan Analisis Gap pada Kualitas Pelayanan Trans Jogja, Jurnal Ilmiah Teknik Industri, Vol. 13, No. 2, Desember 2014.

Tupamahu \& Hamka, 2017, Analisis Kepuasan Konsumen Roti Studi Kasus pada Golden Bakery Ternate, Jurnal Ilmiah Agribisnis dan Perikanan, Vol 10, No.1, Mei 2017.

Tjiptono, F, 2012, Service Management mewujudkan layanan prima. Edisi ke 2. Yogyakarta : PT. ANDI

Wahyu, A. D, 2004, Pengendalian Kulitas Statistik. Yogyakarta: ANDI. 